\title{
A DECISÃO ESTRATÉGICA DA LOCALIZAÇÃO E O SURGIMENTO DOS TECNOPOLOS: O CASO DE SÃO JOSÉ DOS CAMPOS
}

\section{THE LOCALIZATION STRATEGICAL DECISION AND THE TECHNOPOLES BORN: THE CASE SÃO JOSÉ DOS CAMPOS}

\author{
MARCELO BRANT BRAGHETTA \\ Graduado em Administração pela Universidade Presbiteriana Mackenzie. \\ Avenida Luciano Gualberto, 908, sala E106, Butantã - São Paulo - SP - CEP 05508-010 \\ E-mail: braghetta@hotmail.com
}

RENATA NAGAI

Graduada em Administração pela Universidade Presbiteriana Mackenzie. Avenida Luciano Gualberto, 908, sala E106, Butantã - São Paulo - SP - CEP 05508-010

E-mail: renagai@hotmail.com

\section{RENATA NAVES TRUITE}

Graduada em Administração pela Universidade Presbiteriana Mackenzie. Avenida Luciano Gualberto, 908, sala E106, Butantã - São Paulo - SP - CEP 05508-010

E-mail: renatatruite@hotmail.com

\section{DORA DA SILVA PEREIRA GALVÃO}

Professora da Universidade Presbiteriana Mackenzie. Avenida Luciano Gualberto, 908, sala E106, Butantã - São Paulo - SP - CEP 05508-010 E-mail:dorapg@mackenzie.br

\section{LUCIANO AUGUSTO TOLEDO}

Professor da Universidade Presbiteriana Mackenzie. Avenida Luciano Gualberto, 908, sala E106, Butantã - São Paulo - SP - CEP 05508-010 E-mail: luciano@mackenzie.br 


\section{RESUMO}

O objetivo do presente trabalho foi identificar os fatores que motivaram as empresas a se estabelecerem em São José dos Campos. A metodologia utilizada para o desenvolvimento do estudo foi a do discurso do sujeito coletivo,realizada a partir de entrevistas com gestores de empresas situadas em São José dos Campos. O resultado da pesquisa comprovou que a escolha da localização das empresas aborda fatores exógenos,forças centrípetas e centrífugas que influenciam no processo de tomada de decisão para a localização e a influência no desenvolvimento regional. O desenvolvimento desta pesquisa possibilitou a comprovação do posicionamento do tecnopolo de São José dos Campos no Projeto Geopolítico da Modernidade Brasileira,nos cenários nacional e internacional,como núcleo de atração para localização de empresas.

\section{PALAVRAS-CHAVE}

Economia espacial; Empresas; Planejamento estratégico; São José dos Campos; Tecnopolos.

\section{ABSTRACT}

This paper aims to identify the factors thathad motivated the companies if to establish in São José dos Campos. The methodology used for the development of the study,considered the analysis of the speech of collective subjectdiscussion from interviews with managers of situated companies in São José dos Campos. The resultof the research proved thatthe choice of the localization of the companies approaches factors exogenous,centripetal forces and centrifugal machines that influence in the process of taking of decision for the localization and the influence in the regional development. The developmentof this research made possible the evidence of the positioning of Technopoles of São José dos Campos in the Geopolitical Projectof Brazilian Modernity,in the scenes national and international as nucleus of attraction for localization of companies. 


\section{KEYWORDS}

Space economy; Companies; Strategically planning; São José dos Campos; Technopoles.

\section{INTRODUÇÃO}

A análise dos mecanismos determinantes para a localização industrial das empresas se configura entre as princi pais preocupações da geografia econômica e da administração empresarial para o desenvolvimento regional. Ao longo das quatro últimas décadas,ela assume uma dimensão particular: o avanço da tecnologia que fez surgir novas atividades cuja lógica da organização espacial é menos conhecida.

Os novos espaços industriais estabelecem uma estruturação territorial inovadora,mas que acompanham a evolução industrial (SANTOS,I994). Conforme Benko (I999), a criação de tecnopolos consiste em políticas adotadas por regiões com estratégias de desenvolvimento econômico apoiadas no potencial universitário e de pesquisa,esperando-se que estimule uma industrialização por iniciativa de empresas de alta tecnologia,criadas no local ou para lá atraídas. A constituição do tecnopolo de São José dos Campos colocou a cidade em projeção internacional. Iniciado em meados da década de I950,o projeto foi resultado da criação de centros técnicos,o qual estava aliado a políticas estatais voltadas para a formação de um complexo tecnológico.

À luz do exposto,justifica-se um estudo que apresente uma análise dos fatores que motivaram as empresas a se estabelecerem em São José dos Campos, abordando,ainda,a emergência dos novos espaços industriais e a lógica da localização espacial das empresas.

\section{METODOLOGIA}

O objetivo do presente trabalho foi estudar os fatores que influenciaram a decisão de empresas pela localização no tecnopolo de São José dos Campos. Utilizou-se a metodologia qualitativa denominada teoria do discurso do sujeito coletivo,que propõe o uso de quatro figuras metodológicas para ajudar a organizar depoimentos e demais discursos: a ancoragem, a idéia central, as expressõeschave e o discurso do sujeito coletivo (DSC) (LEFÈVRE; LEFÈVRE,2003). 
Para efeito de análise dos depoimentos,a idéia central pode ser entendida como a síntese do conteúdo discursivo explicitado pelos sujeitos. Esse processo baseia-se nas afirmações,negações e dúvidas a respeito da realidade baseada em fatos,bem como nos juízos de valor sobre a realidade institucional e o contexto em que os sujeitos estão envolvidos (SIMIONI etal.,I997).

Simioni etal. (I997) relatam que o discurso do sujeito coletivo consiste em uma estratégia metodológica que objetiva tornar mais clara uma dada representação social. É a reunião,em um só discurso-síntese, de vários discursos individuais emitidos como resposta a uma mesma questão de pesquisa demandada por sujeitos sociais que fazem parte de uma mesma cultura organizacional ou grupo. Os autores concluem que o DSCé uma forma de expressar diretamente a representação social de um determinado sujeito social.

Para a coleta de dados, foi utilizada a entrevista não-estruturada,aplicada em uma amostra não-probabilística constituída por executivos e funcionários de empresas situadas no município de São José dos Campos e por autoridades que trabalham na prefeitura da cidade. Ao todo,entrevistaram-se sete pessoas: cinco representantes de empresas privadas (Johnson e Johnson,Kodak,General Motors,Tech Net,Future Kids) e dois representantes da prefeitura (assessores da Secretaria de Desenvolvimento Econômico). Os dados obtidos foram analisados conforme a metodologia do discurso do sujeito coletivo (DSC).

Lefèvre e Lefêvre (2003) ensinam que a metodologia do DSCrepresenta um discurso-síntese elaborado com pedaços de discursos. Esse método consiste em uma técnica de tabulação e organização de dados qualitativos,a qual resolve um dos grandes impasses da pesquisa qualitativa,pois permite,por meio de procedimentos sistemáticos e padronizados, agregar depoimentos sem reduzi-los a quantidades. Essa técnica consiste basicamente em (LEFRÈVE etal.,2000):

- Leitura do conjunto dos depoimentos coletados nas entrevistas;

- Leitura da resposta a cada pergunta em particular,marcando as expressõeschave selecionadas;

- Identificação das idéias centrais de cada resposta;

- Análise de todas as expressões-chave e idéias centrais,agrupando as semelhantes em conjuntos homogêneos;

- Identificação e nomeação da idéia central do conjunto homogêneo,que será uma síntese das idéias centrais de cada discurso;

- Construção dos discursos do sujeito coletivo de cada quadro obtido na etapa anterior;

- Atribuição de um nome ou identificação para cada um dos discursos do sujeito coletivo. 


\section{REFERENCIAL TEÓRICO}

\subsection{REFLEXÃO TEÓRICA SOBRE OS CONCEITOS DE TECNOPOLO}

Segundo Medeiros e Perilo (I990),os tecnopolos surgiram da percepção de que os avanços científicos e tecnológicos são impostos por novos padrões ao desenvolvimento econômico. Esses avanços provocaram radicais alterações nas economias de escala,reduzindo o peso das vantagens comparativas dos países de desenvolvimento tardio em relação ao uso da mão-de-obra e ao uso de recursos naturais.

Para Torkomian (I996),o objetivo dos tecnopolos consiste em agregar ações que facilitem e acelerem o surgimento de produtos,processos e serviços,em que a tecnologia adquire o status de insumo de produção fundamental. Medeiros e Perilo (I990) citam alguns dos objetivos relacionados aos tecnopolos:

- Promover a criação e consolidação de empresas de base tecnológica;

- Fornecer suporte gerencial por meio de consultoria e cursos nas áreas de gestão tecnológica e gestão empresarial às empresas e ao setor acadêmico;

- Facilitar a interação sistemática entre as empresas e instituições de ensino e pesquisa, possibilitando o uso de recursos humanos, equi pamentos e laboratórios,inclusive de forma compartilhada;

- Viabilizar o envolvimento de instituições financeiras (inclusive capital de risco) e governamentais, enfatizando a partici pação dos governos federal, estadual e municipal.

Os tecnopolos correspondem a rea lizações utilizadas por cidades cujas estratégias de desenvolvimento econômico se apóiam na valorização de seu potencial universitário e de pesquisa,e espera-se que este provoque uma industrialização nova por iniciativas de empresas de alta tecnologia,criadas no local ou para lá atraídas (BENKO,I999).

Conforme Benko (1999), a reunião,em um mesmo lugar das atividades de alta tecnologia,centros de pesquisa,empresas e universidades, assim como de organismos financeiros que facilitem os contatos pessoais entre esses meios, cria a sinergia que possibilita o surgimento de idéias novas e técnicas,suscitando,portanto,criações de empresas. Ainda,segundo o mesmo autor,o tecnopolo consiste em um agrupamento de organizações de pesquisa e de negócios que se ligam ao desenvolvimento científico. É constituído de empresas (na maioria pequenas e médias), escritórios, laboratórios e unidades de fabricação. O tecnopolo designa um espaço preciso,o ponto singular de um território onde se con- 
centram e se irrigam mutuamente as atividades econômicas estreitamente ligadas às novas técnicas, fundadoras, por seu caráter inovador, do desenvolvimento futuro. Ainda, segundo esse autor,os pólos tecnológicos não correspondem a pontos de polarização,mas a organizações funcionais de competência científica existentes nas regiões. O tecnopolo se organiza em redes que visam,sobretudo,à transferência de tecnologia para a indústria regional,o que permite que diferentes parceiros trabalhem juntos (BENKO,I999).

\subsection{CONSTITUIÇÃO DOS TECNOPOLOS NO BRASIL}

A criação de um ambiente favorável à fundação de novas empresas de base tecnológica e à indução da inovação,como fator primordial da competitividade das empresas nacionais, esteve entre os princi pais motivos para a fundação de tecnopolos na primeira metade da década de i980,em território brasileiro (PERUSSI, 200I). Para Torkomian (I996), no Brasil os tecnopolos surgiram como reflexo de um processo ocorrido em países de Primeiro Mundo,onde foi criada uma série de parques tecnológicos, próximos a campos universitários, destinados a abrigar empresas de alta tecnologia.

Segundo Medeiros e Perilo (I990),os tecnopolos não se criam por projeto ou decreto,eles surgem de precondições existentes em determinado local. Esses autores definem um conjunto de quatro componentes necessários para a existência de um tecnopolo:

- Existência de instituições de ensino e pesquisa;

- Aglomeração de empresas interessadas em desenvolvimento tecnológico;

- Existência de projetos de inovação tecnológica conjuntos (empresa-universidade);

- Estrutura organizacional (formal ou informal) apropriada.

Medeiros e Perilo (I990) afirmam que no Brasil os pólos tecnológicos distinguem-se em três formatações:

- Pólo com estrutura formal: as empresas e instituições de ensino e pesquisa dispersam-se pela cidade,porém existe uma entidade coordenadora,formalmente constituída,encarregada da aceleração de criação de empresas,facilitando a inovação tecnológica. Existem ainda,eventualmente,incubadoras para abrigar as empresas nascentes. No Brasil,alguns exemplos localizam-se em Curitiba,Campina Grande e Florianópolis,Campinas e São Paulo.

- Parque tecnológico: as empresas estão reunidas em um mesmo local,perto do campus da universidade; existe uma entidade coordenadora que facilita 
a integração e o gerenciamento do pólo. Os terrenos estão disponíveis para venda ou locação e abrigam incubadoras ou condomínio de empresas. Dessa forma estão estruturados os parques tecnológicos ao redor do mundo,em estrutura que cidades como São Paulo e Campinas estão buscando.

- Pólo comestrutura informal: as empresas e instituições de ensino e pesquisa estão dispersas na cidade,mas existem ações sistematizadas e projetos que, de alguma forma,proporcionam interações entre os agrupamentos,apesar de não haver um órgão formal,concebido para facilitar a integração entre eles. São José dos Campos pode ser considerado um exemplo de pólo com estrutura informal.

Segundo Torkomian (1996), a fim de fomentar o surgimento de empresas de base tecnológica,o governo brasileiro começou a incentivar o surgimento de pólos tecnológicos,conforme se verifica no Quadro I.

\section{QUADRO I}

\section{PRINCIPAIS TECNOPOLOS BRASILEIROS}

\begin{tabular}{|c|c|c|}
\hline CIDADE & ESTADO & ÁREAS PREDOMINANTES DO CONHECIMENTO \\
\hline Campina Grande & PB & Eletroeletrônica, informática e telecomunicações \\
\hline Santa Rita do Sapucaí & MG & Eletrônica e comunicações \\
\hline Petrópolis & RJ & Biotecnologia \\
\hline Rio de Janeiro & RJ & Desenvolvimento tecnológico das indústrias e biotecnologia \\
\hline Campinas & SP & Alta tecnologia. \\
\hline São Carlos & SP & $\begin{array}{l}\text { Novos materiais, ótica, informática, instrumentação e } \\
\text { mecânica de precisão }\end{array}$ \\
\hline São José dos Campos & SP & Alta tecnologia, aeronáutica, química e farmacêutica \\
\hline Curitiba & PR & $\begin{array}{l}\text { Informática, eletroeletrônica, mecânica de precisão, micro- } \\
\text { eletrônica, biotecnologia, química fina, novos materiais e } \\
\text { tecnologia de alimentos }\end{array}$ \\
\hline Florianópolis & SC & Informática, mecânica de precisão e eletrônica \\
\hline Joinvile & SC & Tecnologia de alimentos e agropecuária \\
\hline Porto Alegre & RS & Eletroeletrônica e mecânica de precisão \\
\hline Santa Maria & RS & Tecnologia de alimentos \\
\hline
\end{tabular}


Para Torkomian (I996),as princi pais experiências são as de Campina Grande,Campinas,Curitiba,Florianópolis, Rio de Janeiro,Santa Rita do Sapucaí,São Carlos e São José dos Campos. A cidade de São Paulo não foi incluída pelo fato de ser antiga e já ter consolidada essa iniciativa,na qual existe inegável capacitação tecnológica,materializada em instituições de ensino pioneiras em pesquisa e desenvolvimento de novas tecnologias.

São José dos Campos destaca-se pelo caráter inovador, sob o aspecto da modernidade,geopolítica,conhecimento e tecnologia,e constitui objeto central de estudo deste trabalho (TORKOMIAN,I996).

\subsection{LOGÍSTICA DA LOCALIZAÇÃO ESPACIAL DAS EMPRESAS}

Para Benko (I999),os procedimentos para o estabelecimento não podem ser generalizados a todas as indústrias, portanto não existe um modelo único para loca lização espacial das empresas. Clemente e Higachi (2000) descrevem o modelo Weber como o mais representativo das Teorias da Localização de Mínimo Custo. Os autores identificam o transporte e a mão-de-obra como os fatores mais importantes ao explicarem a localização das empresas entre as regiões. Segundo Bernardes e Marcondes (2000), a decisão de localizar uma instalação empresarial torna-se relevante,pois o local necessita ser adequado e garantir um número mínimo de clientes. As concentrações têm de ser bem analisadas,já que elas permitem um aumento dos clientes e fornecedores.

O peso de cada fator que influencia na decisão da localização varia muito de acordo com o ti po de negócio,as regras são gerais,porém cabe ao empreendedor adaptá-las à sua empresa. Bernardes e Marcondes (2000) sugerem cinco funções administrativas para a classificação dos fatores relevantes quanto à escolha da localização de um estabelecimento:

- Fatores relacionados às vendas: procurar analisar as exigências do cliente (deslocamento do cliente,facilidade de encontrar o produto procurado,prazo de entrega e insta lações de boa aparência) e adaptar-se sempre a elas.

- Fatores relacionados à produção: relacionam-se aos aspectos internos da empresa (estrutura do processo produtivo,áreas disponíveis para futuras expansões e planta das instalações).

- Fatores relacionados às compras: comumente esses fatores são de grande número (logística de insumos e produtos acabados e proximidade com fornecedores).

- Fatores relacionados às finanças: custos do imóvel e das instalações.

- Fatores relacionados à mão-de-obra: facilidade em encontrar mão-de-obra especializada,treinamento dos colaboradores,cultura interiorizada e apoio dos sindicatos. 


\subsection{FATORES DE LOCALIZAÇÃO}

Benko (I999) apresenta a necessidade de estudar as variáveis envolvidas na organização espacial das empresas. Segundo o autor,vários enfoques têm sido propostos,e o primeiro baseia-se no esquema geral das localizações interdependentes. Nesse esquema,os trabalhos empíricos enfatizam o interesse nos lucros e nas decisões individuais,assim o princípio da melhor loca lização está ligado a custos de transporte,custos de obtenção de matéria-prima,determinação dos investimentos em implantação,dentre outros. Segundo essas teorias,as empresas determinam suas localizações com base nas vantagens comparativas que os espaços oferecem em relação a esses diferentes fatores. O conjunto dessas teorias pode ser classificado como teorias de localização weberiana. O objetivo da teoria das loca lizações é fornecer explicações da organização espacial das empresas,identificar as variáveis que determinam a localização e oferecer soluções analíticas. Deve também trazer respostas detalhadas às numerosas questões relativas à explosão espacial das empresas e à influência do meio ambiente (BENKO, I999).

De acordo com Benko (I999), os conhecimentos teóricos atuais são insuficientes,a teoria da localização está em crise e a concepção weberiana perdeu o interesse e não nos informa sobre o comportamento industrial contemporâneo. A teorização atual procura fatores de localização exógenos,específicos das indústrias de alta tecnologia,que condicionam a implantação e o desenvolvimento dessas indústrias em uma dada região.

\subsection{FATORES DE LOCALIZAÇÃO EXÓGENOS}

Segundo Benko (1999), as empresas necessitam tanto de capital humano altamente qualificado (executivos) como também de mão-de-obra barata para serviços de fabricação rotineira. Essa dualidade social define as características do espaço,pois o local deve ser percebido como aprazível,promovendo bem-estar para os moradores. Fator este fundamental para atração e retenção da mão-deobra. Para o mesmo autor, a proximidade de universidades e institutos de pesquisa representa um elemento básico que possibilita a integração de pesquisa e tecnologia,além de ser uma importante fonte de mão-de-obra qualificada. O local deve ter atrativos para essa força de trabalho,ou seja,a paisagem deve ser estimulante,de maneira a propiciar um meio ambiente saudável que ofereça condições para que as pessoas possam desfrutar de uma boa qualidade de vida (lazer,eventos culturais,escolas, universidades,centros comunitários etc.).

Benko (I999) apresenta também a importância do transporte. A região deverá dispor de aeroportos,rodoviárias e ferrovias,facilitando assim o fluxo de 
insumos e pessoas,além de atender ao mercado consumidor,ou seja,o custo de distribuição do material produzido. Os serviços representam elementos fundamentais para o desenvolvimento da alta tecnologia. É necessária a construção ou adaptação de uma rede de suporte para instalação das empresas,com uma eficiente rede hoteleira,de restaurantes e serviços em geral. Um clima político e de negócios favorece a instalação das empresas,principalmente ao se considerar o planejamento de suas atividades (BENKO,I999); dessa forma,o papel dos poderes públicos também consiste em fator relevante para a localização (CASTELLS; HALL,I994).

\subsection{FORÇAS CENTRÍPETAS E CENTRÍFUGAS DA LOCALIZAÇÃO}

Segundo Fujita etal. (2002), para uma economia ser estável,ela depende do equilíbrio entre duas forças: centrípeta e centrífuga. Ainda,segundo os autores,a diferença entre elas é que as forças centrípetas tendem a promover a concentração espacial das atividades,enquanto as forças centrífugas se opõem a tal concentração. Um exemplo disso ocorre quando um trabalhador abandona uma região com produção industrial concentrada,parte para outra região qualquer e descobre que fazendo isso seu sa lário real aumenta; se o sa lário aumentar,a concentração de produção industrial não será um equilíbrio. Se o trabalhador parte de um equilíbrio no qual a produção industrial se encontra igualmente dividida pelas duas regiões,um movimento de pequeno número de trabalhadores de uma região para outra aumenta ou diminui o salário relativo na região de destino; se isso aumentá-lo,a situação simétrica inicial será instável em relação a pequenas perturbações (FUJITA etal.,2002). Esse conceito colabora para demonstrar de que forma as empresas estão organizadas,distribuídas e estruturadas no tecnopolo de São José dos Campos.

\subsection{TOMADA DE DECISÃO E LOCALIZAÇÃO DAS EMPRESAS}

A tomada de decisão engloba um processo de identificar um problema e selecionar uma linha de decisão para enfrentá-lo ou para aproveitar uma oportunidade. As decisões podem ser de duas maneiras: programadas ou não-programadas. As decisões programadas podem ser tratadas por meio de políticas, procedimentos e regras,já as não-programadas envolvem problemas incomuns ou excepcionais. A maioria das decisões envolve algum elemento futuro. Os administradores devem ser capazes de analisar a certeza,o risco,a incerteza ou a turbulência de cada alternativa (STONER; FREEMAN,2000).

Segundo Ballou (2004),encontrar um local certo para insta lação representa um fator muito importante dentre todas as tomadas de decisão para o negócio, 
essa determinação envolve números da localização e do tamanho das instalações a serem utilizadas. Faz-se necessário levar em consideração a existência de portos,fornecedores,armazéns, filiais de varejo,centros de serviço e consumidores finais. O autor define que a localização tem de ser definida conforme uma ordem de classificação dos problemas: força direcionada,número de instalações,escolhas discretas,grau de agregação de dados e horizonte de tempo.

Para Chopra e Meindl (2004), as decisões sobre instalações também são denominadas decisões do projeto da rede de cadeia de suprimento. Nessa rede, define-se o papel que cada instalação exercerá no que se refere aos processos desencadeados,o lugar a ser localizada,a capacidade alocada em cada instalação,os mercados a serem servidos pelas instalações e as fontes de suprimentos que alimentam as instalações. Todas as decisões de localização relacionam-se e devem ser tomadas diante dessa perspectiva. O papel de cada instalação é importante,pois define o grau de flexibilidade próprio para atender à demanda,decisão que causa impacto na estratégia organizacional em longo prazo. Mudar de localidade implica custo muito elevado,por conseqüência a empresa tem de se manter no território escolhido por longo tempo (CHOPRA; MEINDL,2004).

Por um lado,o local a ser escolhido pode,de forma agressiva,causar impacto nos custos envolvidos do produto final,uma boa decisão permite uma razoável redução nos custos da empresa; por outro,uma má decisão de localização dificulta o desempenho eficiente da cadeia de suprimentos. A alocação de capacidade também exerce papel expressivo,podendo diminuir ou aumentar os custos totais do produto se houver uma capacidade ociosa. A existência de fontes de suprimentos e mercados para instalações exerce influência no desempenho porque afeta os custos de produção total,o estoque e o transporte,contraídos pela cadeia de suprimentos para satisfazer a demanda do cliente (CHOPRA; MEINDL,2004).

Na concepção de Chopra e Meindl (2004), existem alguns fatores que influenciam nas decisões de instalação das empresas:

- Fatores estratégicos: a estratégia competitiva influencia muito na decisão de instalação,empresas que priorizam custos tendem a se instalar em locais mais baratos,as que priorizam responsabilidade se instalam perto dos mercados consumidores ou locais de fácil acesso,e as que têm como objetivo o mercado internacional se localizam em diversos países do mundo.

- Fatores tecnológicos: as tecnologias de produção disponíveis exercem um impacto significativo nas decisões de localização. No caso de economia de escala expressiva,a melhor decisão corresponde a optar por poucos locais com alta capacidade; na situação inversa,com custos fixos baixos,as instalações devem ser em vários locais. 
- Fatores macroeconômicos: à medida que o comércio foi se globalizando,os fatores macroeconômicos (impostos, tarifas, taxas de câmbio e outros fatores econômicos) se tornaram vitais para o sucesso ou fracasso de uma cadeia de suprimentos. Os incentivos fiscais oferecidos por muitas regiões que estão procurando o desenvolvimento local, na maioria das vezes, constituem o fator-chave na decisão de instalação de uma empresa. Países em desenvolvimento geralmente criam zonas de livre-comércio,onde taxas e tarifas são reduzidas desde que a produção seja essencialmente destinada à exportação. As empresas internacionais apreciam esse incentivo,principalmente pela oportunidade de explorar a mão-de-obra barata local. As flutuações da taxa de câmbio,a estabilidade política do país em questão e a disponibilidade de boa infra-estrutura também são fatores que impactam a decisão de localização.

- Fatores competitivos: para escolher o local onde se instalará,a empresa deve considerar a estratégia,o tamanho e local dos concorrentes. A maneira como as empresas competem entre si e fatores externos como mão-de-obra e matériaprima geralmente as obrigam a ficar perto de seus concorrentes. Outros fatores que levam as empresas a se instalarem perto umas das outras são os benefícios por geração de demanda e infra-estrutura,que várias empresas do mesmo setor têm a condição de proporcionar,mais do que se estivessem isoladas.

- Tempo de resposta ao cliente e presença local: empresas cujos clientes exigem tempo rápido de resposta precisam localizar-se perto deles. Em contrapartida,as companhias cujos clientes toleram um tempo de resposta mais longo exigem menos locais e podem se concentrar no aumento da capacidade de cada local.

- Custos de logística e instalações: levam em conta os custos de estoque e de transporte tanto de entrada (contraídos na chegada de material à instalação) como de saída (contraídos ao enviar material de uma instalação).

\subsection{ESTABELECIMENTO DAS EMPRESAS NO TECNOPOLO DE SÃO JOSÉ DOS CAMPOS}

A década de I960 marca,no mundo todo,a definição de um novo paradigma,caracterizado pela tecnificação e cientificização do espaço. Nesse momento, a atuação do Estado foi imprescindível,pois esses vetores só se tornaram possíveis por meio da atuação estatal,implantando os novos sistemas de informação e comunicação. Desse modo,a constatação de que o domínio do vetor científico e tecnológico constitui a premissa fundamental para o desenvolvimento no mundo contemporâneo levou o Estado brasileiro a concentrar seus esforços nesse projeto,o denominado Projeto Geopolítico da Modernidade (BECKER; EGLER,I989). 
O projeto tecnológico de São José dos Campos foi resultado tanto do processo de desconcentração industrial de São Paulo como das políticas estatais especificamente voltadas para a formação de um complexo tecnológico nas áreas bélica,espacial,aeronáutica e de eletrônica avançada,cujo fundamento geopolítico assentou-se na questão da Segurança Nacional. A respeito desse tema,Medeiros e Perilo (I990) esclarecem que essas áreas correspondem a setores considerados estratégicos para o desenvolvimento nacional e,portanto,tiveram forte apoio governamental via financiamentos diretos ou por meio de seu poder de compra.

Medeiros e Perilo (I990) consideram que,como forma de incrementar o nível científico e tecnológico da aeronáutica nacional e atender a uma antiga reivindicação da corporação militar,foi concebida a instalação de um centro de capacitação científica e tecnológica dentro do próprio Ministério da Aeronáutica: Centro Técnico Aeroespacial (CTA). A escola criada foi fruto da constatação de que,para que houvesse a formação de um parque tecnológico no Brasil,era necessária a existência de mão-de-obra qualificada,daí o investimento em formação de pessoal.

Com relação à loca lização,partiu-se do princípio geopolítico de que ele deveria estar fora das grandes cidades (Rio de Janeiro e São Paulo), mas,ao mesmo tempo,estar suficientemente perto delas para permitir o intercâmbio de professores e técnicos com outras escolas de nível superior,instituições de pesquisa e desenvolvimento e com a indústria. Nesse contexto,o município de São José dos Campos dispunha dessa característica - a proximidade com São Paulo corresponde a cem quilômetros. Ademais,considera-se sua localização estratégica pela proximidade com o litoral (portos de Santos e de São Sebastião) e pelas ligações que possui com Minas Gerais,em direção ao interior do Brasil (Prefeitura Municipal de São José dos Campos,200I).

Medeiros e Perilo (I990) acrescentam a esses fatores a existência,até o início da década de 1970, de terrenos relativamente baratos e de uma infra-estrutura urbana adequada para absorver um contingente operário que eventualmente para lá se dirigisse. Essas condições atraíram empresas,sobretudo multinacionais,que se instalaram basicamente ao longo do município de São José dos Campos.

Durante a década de ig60,começam a se instalar no município as empresas nacionais (privadas e estatais) que mais tarde viriam a compor os parques aeronáutico e bélico. Em I96r,instala-se o Instituto Nacional de Pesquisas Espaciais (Inpe) para atender a dois objetivos básicos (MEDEIROS; PERILO,I990):

- Criar uma organização que pudesse realizar atividades relacionadas com a utilização do espaço;

- Preparar um núcleo de pesquisadores capaz de tratar dos problemas espaciais e de interagir com grupos de estudos semelhantes de outros países. 
Durante a década de i960,algumas das empresas de base tecnológica que se instalaram no município foram a Avibras (I961),Tecnasa (ig62) e Amplimatic (I964), dando início,em São José dos Campos, ao processo de aglomeração de empresas de base tecnológica nas áreas espacial e bélica.

Negri (1996) esclarece,ainda,que na esfera do setor produtivo estatal deve ser mencionada a implantação,em ig69,da Embraer,em São José dos Campos, prioridade do Ministério da Aeronáutica consubstanciada nas metas e bases para a ação do governo,destinada à produção de aviões,inicialmente do avião bimotor turboélice "Bandeirante" e de outros aviões de treinamento para a formação avançada de pilotos.

Como funcionavam em São José dos Campos, desde I950,o Centro Tecnológico da Aeronáutica (CTA) e o Instituto Tecnológico de Aeronáutica (ITA), o governo federal propôs para essa região apoio ao desenvolvimento científico e tecnológico nacional,com um programa de pesquisa e desenvolvimento,que compreende a instalação de laboratórios especializados no CTA e o projeto de tecnologia dos Metais Estratégicos para Aeronaves da FAB e outras pesquisas de desenvolvimento importantes.

A década de I960 representou,então,um marco importante para a instalação de empresas no município de São José dos Campos,e a partir da década de I980 esse fenômeno voltou a ocorrer com mais intensidade. Nesta década,instalaram-se no município algumas empresas,tais como: Composite (I98I),ABC (1984),Engespaço (1983),Quantum (I987) e Imagem (1986).

Já em I980,é instalada,no município de São José dos Campos,a Refinaria Henrique Lage,que passou a responder por 12,5\% do sistema de refino de petróleo no Brasil. Essa empresa estimulou a vinda de outras empresas ligadas principalmente aos ramos mecânico, de materiais elétricos, de materiais de transporte e metalúrgico,que passaram a empregar o maior número de pessoas nesse período (NEGRI,I996).

Nessa época foram implantadas no município também a Orion (I982) e a Órbita Sistemas Aeroespaciais (I986). A maioria dessas empresas era de capital privado ou pertencia ao Estado,e a escolha do município de São José dos Campos para sediar suas unidades de produção se deu em virtude da já existente infra-estrutura urbana e também da concentração de outras empresas do ramo,gerando o que se denomina de Economias de Aglomeração. Constituiu-se,assim,o Pólo Tecnológico de São José dos Campos,que coloca a cidade em projeção internacional e exibe produtos de alto conteúdo tecnológico,como foguetes,aviões e satélites.

A localização privilegiada,a liada à alta concentração de empresas reconhecidamente bem estruturadas, revela a posição da cidade de São José dos Campos no cenário nacional e internacional,e constitui fator de alta atratividade para outras empresas insta larem-se nesse tecnopolo. 
Conforme dados da Prefeitura Munici pal de São José dos Campos (200I),as regiões do município estão assim caracterizadas:

- Região Norte: a industrialização do principal pólo norte foi desenvolvida a partir da década de I950, predominando os ramos têxteis,cerâmicos e produtos a limentares,com I0,7\% de indústrias e 2,9\% de pessoas ocupadas.

- Região Leste: o eixo pelo sistema leste abrange as indústrias de transporte e de comunicação, metalúrgica, mecânica, minerais não-metálicos, produtos a limentares,mobiliário e madeira,que possuem corredores de fácil acesso, pelo sistema da Rodovia Presidente Dutra e cidades vizinhas. Éa princi pal beneficiada por uma embrionária tendência de dispersão industrial,já que sua partici pação no setor secundário apresenta notável crescimento,com I6,5\% de indústrias e 35,2\% da mão-de-obra ocupada.

- Região Sul: trata-se de uma das regiões mais industrializadas do município, a qual foi desenvolvida a partir do maior pólo industrial ao longo da Rodovia Presidente Dutra,que é considerado o segundo eixo industrial no Vale do Paraíba,envolvendo centros e diversos bairros de São José dos Campos. Implantaram-se indústrias modernas e de alta capitalização. É o caso dos ramos de material elétrico e de comunicações,vestuários,calçados e artefatos de tecidos,química,metalúrgica e mecânica. Esse crescimento deve-se, em grande parte,à concentração de indústrias de médio e grande portes e à formação de importantes distritos industriais nos arredores,com 44,4\% de indústrias e $28,2 \%$ de pessoal ocupado.

- Região Centro: é considerada uma das regiões de maior concentração de indústrias de madeiras,mobiliário,vestuário,calçados e artefatos de tecidos, produtos alimentares,editorial e gráfica,material elétrico e de comunicação, química,minerais não-metálicos e outras.

- Região Sudeste: apresenta uma pequena partici pação do setor secundário do município,onde ocorreu um lento processo de crescimento,com 22,1\% da mão-de-obra ocupada e 4,2\% de indústrias. O Sudeste,evidentemente,não está perdendo indústrias. Ele está crescendo num ritmo mais lento que as demais regiões,onde se localizam as indústrias de produtos aeronáuticos com maior número de pessoal ocupado e outros equi pamentos de transportes.

- Região Oeste: é um dos setores industriais que respondem por uma parcela menor de pessoas ocupadas,com 7,2\% e 4,8\% de indústrias. É uma região que possui indústrias de grande porte,nos ramos de material elétrico e de comunicação,indústrias químicas,veículos automotores e outras. 


\section{RESULTAdOS DA PESQUISA}

Como é proposto na técnica do discurso do sujeito coletivo,os resultados que se seguem foram elaborados com base nas respectivas idéias centrais,recorrendo-se às falas literais das pessoas, conforme já se afirmou anteriormente. Dessa forma,o resultado da pesquisa caracterizou-se pela reconstrução,com base nas respostas individuais, de quantos discursos-síntese foram necessários para expressar uma representação social. Não houve,porém,a busca pela unificação dos discursos em uma única categoria,pois os discursos não se anulam (LEFÈVRE; LEFÈVRE,2003).

Foi possível caracterizar nove idéias centrais,que são:

- Discurso I -Características do meio ambiente: numa decisão de localização da empresa,um fator muito importante foi a qualidade do ambiente que a cidade apresentava. São José dos Campos possui características geográficas peculiares,como um ótimo clima,uma boa qualidade do ar,planalto,recursos hídricos abundantes e grandes extensões de terreno,o que possibilita futura expansão da empresa (novas instalações);

- Discurso 2 -Infra-estrutura de transporte: São José dos Campos tem uma ótima infra-estrutura de transporte,grande número de rodovias próximas como a Rodovia Presidente Dutra,a Carvalho Pinto e a Trabalhadores,e possui um anel viário muito bom e um aeroporto. Toda essa conjuntura,além de dispersar o trânsito,facilita o acesso à cidade tanto para escoamento dos produtos acabados como para a entrada de matérias-primas.

- Discurso 3 -Universidades e centros de pesquisa: um dos maiores atrativos de São José dos Campos para instalação das empresas corresponde à quantidade de mão-de-obra qualificada. Na cidade estão localizadas cinco universidades, vários cursos técnicos bons e importantes centros de pesquisa. A cidade é conhecida pelo seu perfil empreendedor desde a época da criação do Inpe,CTA e ITA,este se destaca pela excelência da qualidade do ensino no campo aeroespacial.

- Discurso 4 -Incentivos fiscais e desenvolvimento do município: a prefeitura de São José não considera uma boa opção a doação de terrenos para a instalação de fábricas na região,pois não acredita que um empresário com visão de futuro se instale na cidade somente porque ganhou uma porção de terra. O que a prefeitura oferece é uma condição para facilitar,atrair e estimular os empresários a se instalarem na cidade,como boa informação,redução do ISS (o que dependerá da quantidade de empregos gerados),redução do IPI e incentivos para promoção cultural e de serviços. 
- Discurso 5-Qualidade de vida: uma das atrações que São José oferece aos empreendedores é a qualidade de vida. Existem diversos centros de lazer, como clubes recreativos, clubes esportivos,shopping center de boa qualidade e condomínios de alto padrão para os empresários construírem suas residências. O trânsito é muito tranqüilo e o nível social econômico é acima da média (o PIB per capita de exportação do Brasil é em média de U\$ 300,00,0 de São José é de U\$ 5.000,00).

- Discurso 6 - Proximidades: há uma preocupação entre os empresários em não se distanciarem muito das metrópoles. A aproximação com grandes metrópoles pode representar uma vantagem competitiva de São José dos Campos. Além de a cidade se localizar no eixo Rio-São Paulo,com fácil acesso a essas duas cidades consideradas as princi pais do país, fica perto dos portos de Santos e São Sebastião,o que facilita muito o escoamento de mercadorias. Muitas empresas também têm necessidade de se localizar perto de seus clientes e/ou fornecedores; como São José dos Campos é um complexo industrial grande,facilita muito essa proximidade.

- Discurso 7-Mentalidade empreendedora: São José dos Campos possui incubadoras e a Sala do Empreendedor da Prefeitura que incentivam e facilitam a formação de perfis empreendedores. Por possuir muitas universidades,a cidade ficou caracterizada pela formação empreendedora de seus jovens que são muito aproveitados nas empresas lá instaladas.

- Discurso 8 - Serviços: muitas empresas prestadoras de serviços se instalaram em São José pela proximidade dos clientes e fornecedores. A cidade apresenta também um ótimo complexo de lojas,restaurantes de ótima qualidade e excelentes hotéis capazes de proporcionar uma estada agradável aos visitantes nacionais e internacionais das empresas instaladas na região.

- Discurso 9 - Histórico da cidade: São José dos Campos era no passado um centro de tratamento de cura para tuberculose. Famosa pelos sanatórios, pacientes com problemas pulmonares iam se tratar pela excelência do clima. A história iniciou-se com um idealista,o brigadeiro Casimiro Montenegro Filho,que implantou o que na época foi considerado uma verdadeira utopia, o Centro Técnico da Aeronáutica (CTA),onde se realizaram estudos de aeronáutica. Por obsessão de Montenegro Filho,criou-se o ITA que se sobressaiu pela excelência da qualidade do ensino no campo aeroespacial. Quando São José dos Campos começou a prosperar,algumas outras regiões industrializadas do Brasil,como São Paulo,já estavam ficando saturadas,o que resultou na diminuição das atratividades desses lugares. Por estas razões São José dos Campos se tornou esse tecnopolo atrativo para as empresas nacionais e multinacionais. 


\section{CONSIDERAÇÕES FINAIS}

A utilização dos instrumentos de análise qualitativa do discurso do sujeito coletivo possibilitou a identificação de nove ti pos de representação social sobre os fatores que motivaram as empresas a se estabelecerem em São José dos Campos: características do meio ambiente,infra-estrutura de transporte,universidades e centros de pesquisa,incentivos fiscais e desenvolvimento do município,qualidade de vida,proximidades,mentalidade empreendedora,serviços e histórico da Cidade. Foi possível verificar que o tecnopolo é um elemento fundamental ao Projeto Geopolítico da Modernidade Brasileira,oferecendo condições de desenvolvimento e sustentabilidade para empresas situadas na região.

A constituição do tecnopolo de São José dos Campos colocou a cidade em projeção internacional a partir de meados da década de I950,resultado de constantes investimentos e da criação de centros técnicos aliados a políticas estatais especificamente voltadas para a formação de um complexo de referência. O desenvolvimento de um ambiente favorável à instalação de novas empresas de base tecnológica e à indicação de inovação como fator primordial de competitividade das empresas esteve entre os princi pais motivos para a criação do pólo tecnológico de São José dos Campos. Isso reflete o processo ocorrido em países de primeiro mundo,onde é incentivada a criação de parques tecnológicos em proximidade a instituições de ensino e de pesquisa.

A análise da pesquisa permitiu a constatação de que a atração e a existência de fatores exógenos e forças centrípetas,como a facilidade dos elementos logísticos,produção de alta tecnologia,mentalidade empreendedora,conveniências, qualidade de vida e instituições de ensino e de pesquisa altamente qualificadas como Inpe,CTA e ITA, estão relacionadas e diretamente ligadas à decisão da loca lização de empresas no município de São José dos Campos.

A diversidade de fatores existentes atrai empresas ligadas à tecnologia e outras que possam se beneficiar destas, como empresas de treinamento, de prestação de serviços, de alimentação e de conveniência,formando,assim,uma rede de integração de negócios. Beneficiando-se do crescimento acelerado de sua população e de pessoas que se deslocam até São José dos Campos para trabalharem e para conhecê-la.

Dessa maneira,tomadas de decisões são ponderadas e analisadas com base em políticas,procedimentos e regras,sempre envolvendo algum elemento futuro,que os administradores deverão analisar,ponderando riscos, incertezas e turbulências econômicas a cada alternativa.

A contribuição desta pesquisa demonstra a atual situação socioeconômica e de desenvolvimento de São José dos Campos,além de servir como base para 
empreendedores e empresários,em relação à tomada de decisões para futuros investimentos em novas empresas, prestações de serviços,e por fim na localização de suas atividades nesse tecnopolo.

\subsection{LIMITAÇÕES DO ESTUDO}

Segundo Salomon (I99I), ao se falar em trabalho acadêmico,não se pode deixar de destacar sua característica essencial,a mesma que remonta a sua origem histórica: a especificação,ou seja,a redução da abordagem a um só assunto, a um só problema. E essa redução é simples de compreender,o método científico de pesquisa parte de um único problema ou de um tema delimitado. Logo, o documento que contém os resultados da pesquisa também tem seus limites preestabelecidos.

A pesquisa utilizada neste trabalho identificou os fatores que motivaram as empresas a se estabelecerem em São José dos Campos,por meio da metodologia qualitativa do discurso do sujeito coletivo. Pela utilização de uma amostra nãoprobabilística,os resultados obtidos com o estudo não permitem generalizações, ou seja,o que foi observado na amostra estudada não necessariamente se refletirá como igual em uma outra amostra a ser utilizada por futuros pesquisadores.

\subsection{RECOMENDAÇÕES PARA TRABALHOS FUTUROS}

Para um melhor aproveitamento do tema aqui estudado,os autores sugerem aos futuros pesquisadores:

- A realização de um comparativo entre a cidade de São José dos Campos com outras cidades semelhantes;

- A rea lização de entrevistas com uma amostra formada de pequenos e médios empreendedores situados na região;

- A utilização de uma metodologia quantitativa em complemento àquela aqui empregada.

\section{REFERÊNCIAS}

BALLOU, R. H. Gerenciamento da cadeia de suprimentos: planejamento, organização e logística empresarial. 4. ed. Porto Alegre: Bookman,200I.

BECKER,B. K.; EGLER,C. A. O embrião do projeto geopolítico da modernidade: o Vale do Paraíba e suas ramificações. Rio de Janeiro: Laget,I989.

BENKO,G. Economia,espaço e globalização: na aurora do século X. São Paulo: Hucitec,I999. 
BERNARDES,C.; MARCONDES,R. C. Criando empresas para o sucesso. 2. ed. rev. e ampl. São Paulo. Futura,2000.

BIASI,M. A experiência dos distritos industriais italianos. Apresentação do Encontro Brasil Empreendedor. São Paulo: Universidade Presbiteriana Mackenzie,2004.

CASTELLS,M.; HALL,P. Technopoles of the world. London: Routledge,I994.

CENTRO DAS INDÚSTRIAS DO ESTADO DE SÃO PAULO (CIESP) - Regional de São José dos

Campos. Guia das indústrias. São José dos Campos: Ciesp,2004.

CHOPRA,S.; MEINDL,P. Supply chain management: strategy,planning and operations. New Jersey:

Prentice Hall,2004.

CLEMENTE,A.; HIGACHI,H. Y. Economia e desenvolvimento regional. São Paulo: Atlas,2000.

FIRMINO,R. J.; CAMARGO,A. R. Espaços inteligentes,cidades da inteligência e regiões dinâmicas em inovação: as novas tecnologias e a configuração urbana e regional. 2000. Dissertação (Mestrado) -Universidade Federal de São Carlos,São Carlos,20oo.

FUJITA,M.; KRUGMAN,P.; VENABLES,A. J. Economia espacial: urbanização,prosperidade econômica e desenvolvimento humano no mundo. São Paulo: Futura,2002.

IEDI. Carta Iedi n. 54: Os sistemas locais de produção/inovação - caras novas na discussão das políticas industrial e tecnológica,2003.

LEFÈVRE,F.; LEFÈVRE,A. M. C. O discurso do sujeito coletivo: um enfoque em pesquisa qualitativa (desdobramentos). Caxias do Sul: Educs,2003.

LEFÈVRE,F.; LEFÈVRE,A. M. C.; TEIXEIRA,J. J. V. O discurso do sujeito coletivo: uma nova abordagem metodológica na pesquisa qualitativa. Caxias do Sul: Educs,2000.

LOPES,A. S. Desenvolvimento regional. Lisboa: Fundação Calouste Gulbenkian,200I.

MEDEIROS,J. A.; PERILO,S. A. Implantação e consolidação de um pólo tecnológico: o caso de São José dos Campos. Revista de Administração de Empresas,São Paulo,v. 30,n. 2,p. 35-45,abr./jun. I990.

NEGRI,B. Concentração e desconcentração industrial em São Paulo (1880-1990). Campinas: Ed. da Unicamp,I996.

NETO,J. A. Redes de cooperação produtivas e clusters regionais. São Paulo: Atlas,I990.

PERUSSI,S. Uma avaliação da contribuição das cooperações universidade-empresa e interempresas para a competitividade das empresas industriais do pólo tecnológico de São Carlos. 200I. Dissertação (Mestrado) -Escola de Engenharia de São Carlos,São Carlos,200I.

PORTER,M. E. The competitive advantage of nations. New York: The Free Press,I998.

PREFEITURA MUNICIPAL DE SÃO JOSÉ DOS CAMPOS. Pesquisa de mão-de-obra e mercado de trabalho. São José dos Campos: Prefeitura Municipal,200I.

SALOMON,D. V. Como fazer uma monografia: elementos de metodologia do trabalho científico. 2. ed. Belo Horizonte: Interlivros,I99I.

SANTOS, M. Técnica, espaço, tempo: globalização e meio técnico-científico informacional. São Paulo: Hucitec,I994.

SEHBE,K. Tecnópoles: passaporte para o futuro. Porto Alegre: [s.n.],I998.

SIMIONI,A.; LEFÈVRE,F.; PEREIRA,I. B. Metodologia qualitativa nas pesquisas em saúde coletiva: considerações teóricas e instrumentais. São Paulo: Faculdade de Saúde Pública da Universidade de São Paulo,I997.

STONER,J. A. F.; FREEMAN,R. E. Administração. Rio de Janeiro: LTC,2000. 
- A DECISÃO ESTRATÉGICA DA LOCALIZAÇÃO E O SURGIMENTO DOS TECNOPOLOS •

MARCELO B. BRAGHETTA • RENATA NAGAI • RENATA N. TRUITE •DORA S. P. GALVÃO • LUCIANO A. TOLEDO

TORKOMIAN,A. L. V. Gestão de tecnologia na pesquisa acadêmica: o caso de São Carlos. I996.

Tese (Doutorado em Administração) - Faculdade de Economia,Administração e Contabilidade, Universidade de São Paulo,I996.

\section{TRAMITAÇÃO}

Recebido em 16/5/2006

Aprovado em $1^{\circ} / 9 / 2007$ 
Copyright of Revista de Administração Mackenzie is the property of Universidade Presbiteriana Mackenzie, RAM-Revista de Administracao Mackenzie and its content may not be copied or emailed to multiple sites or posted to a listserv without the copyright holder's express written permission. However, users may print, download, or email articles for individual use. 